\title{
Holter Monitörü için Elektrokardiyografi Sinyali Tabanlı Yeni Bir Kan
} \section{Basıncı Hesaplama Yöntemi \\ A New Method for Calculating Blood Pressure Based on Electrocardiography Signal for Holter Monitor}

\author{
${ }^{1}$ Muhammed Kürşad UÇAR* \\ ${ }^{1}$ IElektrik-Elektronik Mühendisliği, Mühendislik Fakültesi, Sakarya Üniversitesi, Serdivan / Türkiye
}

\section{Özet:}

Amaç ve Kapsam: Hipertansiyon hastalarında tansiyonun gün içerisinde takip edilmesi ve ilaç tedavisi ile kontrol alınması hayati öneme sahiptir. Hipertansiyonun takibi sürekli kan basıncı takibi sistemleri ile yapılabilir. Ancak bu cihazların vücuda verdiği rahatsızlığı gidermek için yeni teknolojilere ihtiyaç duyulmaktadır. Bu kapsamda, çalışmanın amacı holter cihazlarına entegre edilebilir, Elektrokardiyografi (EKG) sinyali tabanlı kan basıncı ölçme yazılım sürecinin geliştirmektir.

Materyal ve Metot: Çalışmada, açık kaynak paylaşımlı, beş sağlıklı bireyin üç günlük ortalama 6'şar saatlik fiziksel aktivite sırasında EKG sinyali ve kan basıncı kayıtları kullanılmıştır. Çalışmada EKG sinyali filtrelenerek 10 saniyelik epoklara ayrılmıştır. 19897 epoktan 25 adet zaman domeninde özellik çıarılmıştır. Çıkarılan özellikler ile makine öğrenmesi tabanlı Sistolik (Büyük) ve Diastolik (Küçük) kan basıncı tahmin modelleri geliştirilmiştir.

Sonuçlar: Sistolik ve diastolik kan basıncı tahmin modelleri R ve MSE performans değerleri sırasıyla $1,0,0112$ ve $1,0,0054$ olarak tespit edilmiştir.

Sonuç: Elde edilen sonuçlara göre makine algoritmaları tabanlı sistolik ve diastolik kan basıncının hesaplanabileceği ve Holter gibi vücuda daha az rahatsızlık veren cihazlara yazılımsal olarak entegre edilebileceği değerlendirilmektedir.

Anahtar Kelimeler: Kan Basıncı, Elektrokardiyografi Sinyali, Makine Öğrenmesi

\begin{abstract}
:
Objective and Background: In patients with hypertension, it is vital to monitor blood pressure during the day and to control it with medication. Hypertension can be monitored with continuous blood pressure monitoring systems. However, new technologies are needed to eliminate the discomfort caused by these devices to the body. In this context, the aim of the study is to develop an Electrocardiography (ECG) signal-based blood pressure measurement software process that can be integrated into Holter devices.

Material and Methods: In the study, ECG signal and blood pressure recordings of five healthy individuals during an average of three days of physical activity of 6 hours were used. In the study, the ECG signal was filtered and divided into 10-second epochs. 25 time domain features were extracted from the 19897 epoch. With the extracted features, machine learning based Systolic (Large) and Diastolic (Small) blood pressure prediction models were developed.

Results: Systolic and diastolic blood pressure prediction models R and MSE performance values were determined as $1,0.0112$ and $1,0.0054$, respectively.

Conclusions: According to the results obtained, it is evaluated that systolic and diastolic blood pressure can be calculated based on machine algorithms and software can be integrated into devices such as Holter that cause less discomfort to the body.
\end{abstract}

Key words: Blood Pressure, Electrocardiography Signal, Machine Learning

*İletişim Sorumlusu Yazar: Adres: Mühendislik Fakültesi, Elektrik-Elektronik Mühendisliği, Sakarya Üniversitesi, 54187, Sakarya TÜRKIYE. E-posta adresi: mucar@sakarya.edu.tr, Telefon: +902642957440 


\section{Giriş}

Hipertansiyon kalbin vücuda taşıdığı kan atardamar duvarlarında oluşturduğu basıncın normalden yüksek olması ile tanımlanan bir kardiyovasküler hastalıktır. Sistolik kan basınının $140 \mathrm{mmHg}$ ve üzeri, diastolik kan basının $99 \mathrm{mmHg}$ üzeri olması hipertansiyonun bir göstergesidir [1]. Hipertansiyon kalp, beyin, böbrek ve diğer hastalık risklerini arttırması sebebiyle sürekli takip edilmesi ve ilaçlarla kontrol altında tutulması hayati öneme sahiptir.

Dünya sağlık örgütü tarafından açıklanan bir raporda hipertansiyon dünyadaki ölüm sebepleri içerisinde üçüncü sıradadır. Her beş kadından biri ve dört erkekten biri olmak üzere dünya genelinde 1.13 milyar hipertansiyon hastası vardır. Sadece her beş hipertansiyon hastasının durumu kontrol altındadır [2], [3].

Sağlık okuryazarlığı hipertansiyon için önemli bir durumdur. Hastanın hastalık hakkında ne kadar bilgisi varsa hastalığın tedavisi ve kontrol altında tutulması o kadar kolay olmaktadır. Ancak bu durum her zaman gerçekleşemediği için teknik bilgi gerekmeyen akıllı giyilebilir cihazlar ile bu durum ortadan kaldırılabilir [4].

Hipertansiyon sessiz katil olarak tanımlanmasının en önemli sebebi bir işaret veya belirti vermemesidir [2], [3]. Bu sebeple kan basıncının sürekli takip edilmesi önemlidir. Hastalığın belirlenmesinin tek yolu sağlık uzmanı tarafından kan basıncının ölçülmesi ve değerlendirilmesidir. Kan basıncının izlenmesi ve yorumlanması için teknik personele ihtiyaç duymayan yeni giyilebilir teknolojilere ihtiyaç duyulmaktadır.

Literatürde kan basıncının ölçülmesi ile ilgili birçok çalışma vardır [5]-[8]. Bu çalışmalar farklı teknik yöntemler içermektedir. Bazı çalışmalarda Fotopletismografi sinyali kullanılırken [5]-[7], diğer bir çalışmada ECG ve PPG birlikte kullanılmıştır [8]. Bazı çalışmalarda elde edilmesi zor bir süreç olan osilometrik dalga formlarıda tercih edilmektedir [7], [9]. Çalışmalarda yöntem olarak sıklıkla makine öğrenmesi ve derin öğrenme yöntemleri tercih edilmiştir [9]. Literatürdeki bu çalışmalar incelendiğinde mikroişlemcilere uygulanabilir uygulamalara ihtiyaç duyulmaktadır.

$\mathrm{Bu}$ çalışmanın amacı Holter Monitörlerine uygulanabilir yapay zeka tabanlı, ECG sinyali kullanarak kan basıncını hesaplama süreci geliştirmektir. Bu amaç doğrultusunda bireylerden toplanan ECG kayıtları 10 saniyelik epoklara bölünmüş ve her epoktan 25 adet özellik çıkarılmıştır. Çıkarılan özellikler özellik seçme algoritması ile azaltılarak sistolik ve diastolik kan basıncı değerleri hesaplanmıştır.

\section{Materyal ve Yöntem}

ECG tabanlı sistolik ve diastolik kan basınçlarının hesaplanabilmesi için Şekil 1'deki uygulama adımları kullanılmıştır. Sistolik ve diastolik kan basıncının hesaplanması için iki ayrı model geliştirilmiştir.

Akışa göre ECG sinyali filtrelenmiş ve 10 saniyelik epoklara bölünmüştür. Ardından her epoktan 25 adet zaman domeninde özellik çıkarımı yapılmıştır. Nihayetinde özellik seçme sonrası yapay sinir ağları ile diastolik ve diastolik kan basıncı değerleri hesaplanmıştır. 


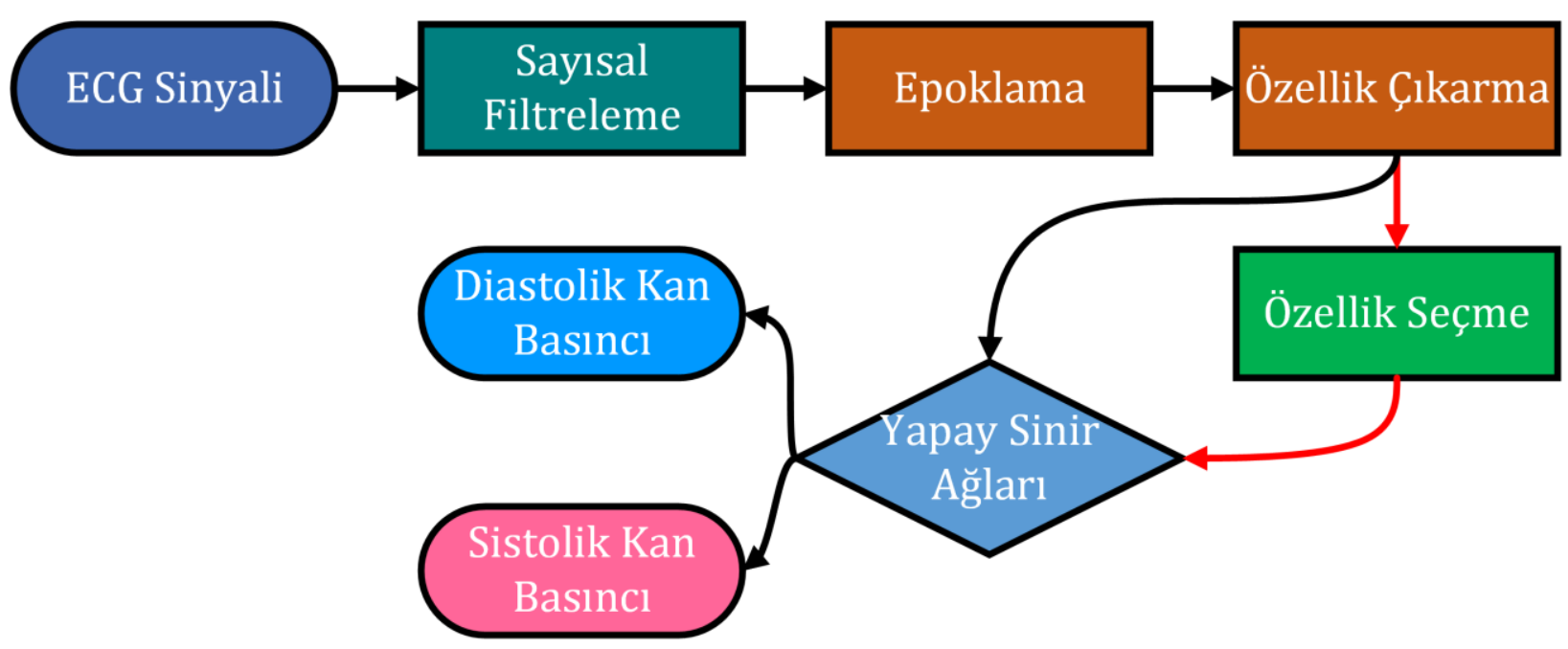

Şekil 1. Çalışma uygulama süreci

\subsection{Verilerin Toplanmast}

Çalışmada açık kaynak kodlu IEEE Dataport veri seti kullanılmıştır [10], [11]. Veri seti dört erkek (28 \pm 6.6) ve bir kadına ait üç günlük ortalama 5-6 saatlik kan basıncı ve ECG değerlerini içerir. Şekil 24 numaralı katılımcının birinci gününe ait kayıtları göstermektedir.

Gün 1 Katılımcı 4


Şekil 2. Günlük veri dağılımı

\subsection{Sinyal Önişleme}

ECG sinyalindeki gürültünün temizlenebilmesi amacıyla 0.25-100 Hz IIR-Chebyshev Type II bant geçiren filtre kullanılmıştır. Kısa sürede kan basıncı değerlerinin hesaplanabilmesi için ECG sinyali 10 saniyelik epoklara ayrılmıştır. Epoklarda kan basıncı sinyali üzerinden diastolik ve 
sistolik kan basıncı değerleri hesaplanmış ve ortalaması alınmıştır. Şekil 310 saniyelik bir ECG epoğunu ve ilgili epok için hesaplanmış sistolik ve diastolik kan basıncı değerlerini göstermektedir.
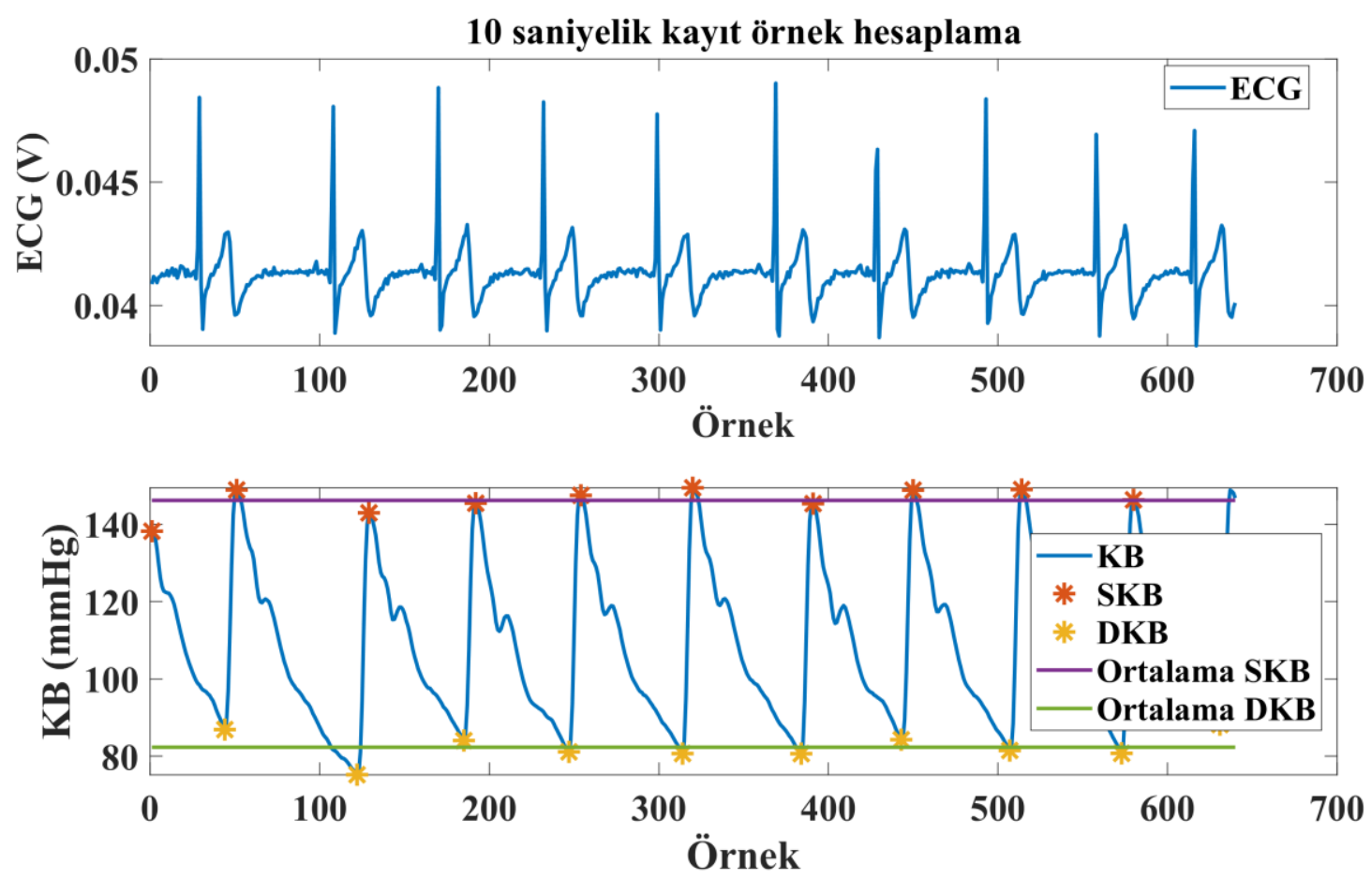

Şekil 3. Kan basıncısın hesaplanması ve grafiksel gösterimi

\section{3. ̈̈zellik Çıkarma}

Tablo 110 saniyelik ECG epoklarından çıkarılan 25 adet özellik çıkarılmıştır. Her özelliğe ait formüller Tablo 1'de özetlenmiştir.

Tablo 1. Özelliklere ait formüller

\begin{tabular}{lll} 
No & Özellikler & Denklem \\
\hline $\mathbf{1}$ & Basıklık (Kurtosis) & $x_{k u r}=\left(\sum_{i=1}^{n}(x(i)-\bar{x})^{4}\right) /\left((n-1) S^{4}\right)$ \\
\hline $\mathbf{2}$ & Çarpıklık (Skewness) & $x_{s k e}=\sum_{i=1}^{n}\left(x_{i}-\bar{x}\right)^{3} /\left((n-1) S^{3}\right)$ \\
\hline $\mathbf{3}$ & $*$ Çeyrekler arası genişlik & $I Q R=i q r(x)$ \\
\hline $\mathbf{4}$ & Değişim katsayısı & $D K=(S / \bar{x}) 100$ \\
\hline $\mathbf{5}$ & Geometrik ortalama & $G=\sqrt[n]{x_{1}+\cdots+x_{n}}$ \\
\hline $\mathbf{6}$ & Harmonik ortalama & $H=n /\left(\frac{1}{x_{1}}+\cdots+\frac{1}{x_{n}}\right)$ \\
\hline
\end{tabular}


Tablo 1. Özelliklere ait formüller (Devamı)

\begin{tabular}{|c|c|c|}
\hline 7 & Hjort parametresi - Aktivite & $A=S^{2}$ \\
\hline 8 & Hjort parametresi - Hareketlilik & $M=S_{1}^{2} / S^{2}$ \\
\hline 9 & Hjort parametresi - Karmaşıklık & $C=\sqrt{\left(S_{2}^{2} / S_{1}^{2}\right)^{2}-\left(S_{1}^{2} / S^{2}\right)^{2}}$ \\
\hline 10 & * Maksimum & $x_{\max }=\max \left(x_{i}\right)$ \\
\hline 11 & Medyan & $\tilde{x}= \begin{cases}\frac{x_{n+1}}{2} & : x \text { odd } \\
\frac{1}{2}\left(x_{\frac{n}{2}}+x_{\frac{n}{2}+1}\right) & : x \text { even }\end{cases}$ \\
\hline 12 & * Ortalama ya da meydan mutlak sapma & $M A D=\operatorname{mad}(x)$ \\
\hline 13 & $*$ Minimum & $x_{\min }=\min \left(x_{i}\right)$ \\
\hline 14 & * Moment, merkezi moment & $C M=$ moment $(x, 10)$ \\
\hline 15 & Ortalama & $\bar{x}=\frac{1}{n} \sum_{i=1}^{n}=\frac{1}{n}\left(x_{1}+\cdots+x_{n}\right)$ \\
\hline 16 & Ortalama eğri uzunluğu & $C L=\frac{1}{n} \sum_{i=2}^{n}\left|x_{i}-x_{i-1}\right|$ \\
\hline 17 & Ortalama enerji & $E=\frac{1}{n} \sum_{i=1}^{n} x_{i}^{2}$ \\
\hline 18 & Ortalama karakök değeri & $X_{r m s}=\sqrt{\frac{1}{n}} \sum_{i=1}^{n}\left|x_{i}\right|^{2}$ \\
\hline 19 & Standart hata & $S_{\bar{x}}=S / \sqrt{n}$ \\
\hline 20 & Standart sapma & $S=\sqrt{\frac{1}{n}} \sum_{i=1}^{n}\left(x_{i}-\bar{x}\right)$ \\
\hline 21 & Şekil Faktörü & $S F=X_{r m s} /\left(\frac{1}{n} \sum_{i=1}^{n} \sqrt{\left|x_{i}\right|}\right)$ \\
\hline 22 & * Tekil değer ayrışımı & $S V D=\operatorname{svd}(x)$ \\
\hline 23 & * \%25 kırpılmış ortalama & $T 25=\operatorname{trimmean}(x, 25)$ \\
\hline 24 & * \%50 kırpılmış ortalama & $T 50=\operatorname{trimmean}(x, 50)$ \\
\hline 25 & Ortalama Teager enerjisi & $T E=\frac{1}{n} \sum_{i=3}^{n}\left(x_{i-1}^{2}-x_{i} x_{i-2}\right)$ \\
\hline
\end{tabular}

* Matlab fonksiyonu kullanılarak elde edilmiştir.

\section{4. Özellik Seçme}

Özellik seçme algoritmaları sinyal işleme yükünü hafifletmek için sıklıkla kullanılır. Bu çalışmada Spearman Korelasyon Katsayıları özellik seçme algoritması olarak kullanılmıştır [12]. Tablo 2'de 
özellikler ile sistolik ve diastolik kan basınçları arasındaki ilişki korelasyon katsayılarına göre özetlenmiştir. Virgülden sonra iki hane kullanılması sebebiyle yuvarlama sonucu değerler 1 gibi çıkmaktadır. Özellikler sıralandıktan sonra gruplandırılarak kan basıncı değerleri tahmin edilmeye çalışılmıştır.

Tablo 2. Özelliklerin kan basıncı değerleri ile ilişki sırası

\begin{tabular}{cccc||cccc}
\multicolumn{4}{c}{} & \multicolumn{2}{c}{ Sistolik } & \multicolumn{4}{c}{ Diastolik } \\
\hline ÖN & $\mathbf{R}$ & ÖN & $\mathbf{R}$ & ÖN & $\mathbf{R}$ & ON & $\mathbf{R}$ \\
\hline 1 & 1.00 & 20 & 1.00 & 1 & 1.00 & 20 & 1.00 \\
\hline 2 & 1.00 & 21 & 1.00 & 2 & 1.00 & 21 & 1.00 \\
\hline 4 & 1.00 & 22 & 1.00 & 4 & 1.00 & 22 & 1.00 \\
\hline 5 & 1.00 & 25 & 1.00 & 5 & 1.00 & 25 & 1.00 \\
\hline 6 & 1.00 & 24 & 1.00 & 6 & 1.00 & 24 & 1.00 \\
\hline 7 & 1.00 & 23 & 1.00 & 7 & 1.00 & 23 & 1.00 \\
\hline 8 & 1.00 & 15 & 1.00 & 8 & 1.00 & 15 & 1.00 \\
\hline 9 & 1.00 & 3 & 1.00 & 9 & 1.00 & 3 & 1.00 \\
\hline 12 & 1.00 & 16 & 1.00 & 12 & 1.00 & 16 & 1.00 \\
\hline 14 & 1.00 & 10 & 1.00 & 14 & 1.00 & 10 & 1.00 \\
\hline 17 & 1.00 & 13 & 1.00 & 17 & 1.00 & 13 & 1.00 \\
\hline 18 & 1.00 & 11 & 1.00 & 18 & 1.00 & 11 & 1.00 \\
\hline 19 & 1.00 & & & 19 & 1.00 & & \\
\hline
\end{tabular}

ÖN: Özellik Numarası, R Korelasyon Katsayısı

\subsection{Yapay Sinir Ăglart}

Yapay sinir ağları (YSA) verilerin tek yönlü aktarıldığı beyin hücrelerinin bir modeli olan en popüler makine öğrenmesi algoritmalarından biridir [13], [14]. Hem sınıflandırma hem de regresyon problemlerinde başarı sonuçlar veren bir algoritmasıdır. Gömülü sisteme entegrasyonun kolay olması farklı bir avantajdır. Pek çok avantajı sebebiyle bu çalışmada kan basıncı hesaplanmasında YSA tercih edilmiştir.

\subsection{Performans Değerlendirme}

Önerilen modellerin performansının test edilebilmesi için Ortalama Karakök Sapması (RMSE), Ortalama Mutlak Yüzde Hata (MAPE), Korelasyon Katsayısı $R$, Açılayıcılık Katsayısı $R^{2}$, Ortalama Mutlak Sapma (MAD) ve Ortalama Hata Karesi (MSE) kullanılmıştır [15], [16].

RMSE, MAPE, MSE, SH ve MAD değerlerinin sıfıra yakın olması $R^{2}$ ve $R$ 'nin ise bire yakın olması model performansının yüksek olduğunun göstergesidir.

\section{Sonuçlar}

Çalışmanın amacı Holter Monitörleri için ECG sinyali ile makine öğrenmesi tabanlı sistolik ve diastolik kan basıncı hesaplamaktır. Çalışma için ECG sinyalleri filtrelenmiş ve 10 saniyelik 
epoklara parçalanmıştır. Epokların 25 zaman domeni özelliği çıkarılmıştır. Özellik seçme algoritması yardımıyla azaltılan veri seti, sistolik ve diastolik kan basıncının hesaplanması için YSA tabanlı tahmin modelleri oluşturulmuştur.

Sistolik kan basıncının hesaplanması için 11 farklı model oluşturulmuştur (Tablo 3). Her modelde farklı seviyede özellik miktarı bulunmaktadır. Seviye 1'de tüm özelliklerin \%5'i olan 1 adet özellik bulunmaktadır. Farklı bir şekilde seviye 5'te tüm özelliklerin \%25'i olan 6 adet özellik bulunmaktadır. Önerilen modellerin R korelasyon değerleri her ne kadar 1 olsa da diğer performans parametreleri bakımından da değerlendirilmelidir. 11 model karşılaştırıldığında tüm özelliklerin kullanıldığı seviye 11 modeli en başarılı tahmin modelidir (Tablo 3, MAPE=0.08). Seviye 2'de MAPE performans değeri 0.18 'dir. Bu değer seviye 11 ile karşılaştırıldığında kullanılabilir makul bir değerdir. Diğer performas değerleri de incelendiğinde seviye 2 modeli pratikte kullanılabilir bir modeldir.

Tablo 3. Sistolik kan basıncı hesaplanması için model performansları

\begin{tabular}{|c|c|c|c|c|c|c|c|c|c|}
\hline \multicolumn{3}{|c|}{ Bilgi } & \multicolumn{7}{|c|}{ Performans Değerlendirme Kriterleri } \\
\hline $\mathbf{S}$ & ÖS & ÖY & MAPE & RMSE & MAD & SH & $\mathbf{R}$ & $\mathbf{R}^{\wedge} \mathbf{2}$ & MSE \\
\hline 1 & 1 & 5 & 0.33 & 0.83 & 0.43 & 0.83 & 1.00 & 1.00 & 0.69 \\
\hline 2 & 3 & 10 & 0.18 & 0.69 & 0.22 & 0.69 & 1.00 & 1.00 & 0.47 \\
\hline 3 & 4 & 15 & 0.29 & 3.35 & 0.40 & 3.35 & 1.00 & 1.00 & 11.21 \\
\hline 4 & 5 & 20 & 0.28 & 0.77 & 0.36 & 0.77 & 1.00 & 1.00 & 0.60 \\
\hline 5 & 6 & 25 & 1.92 & 3.58 & 2.57 & 3.58 & 1.00 & 1.00 & 12.80 \\
\hline 6 & 8 & 30 & 1.31 & 3.80 & 1.71 & 3.80 & 1.00 & 1.00 & 14.43 \\
\hline 7 & 9 & 35 & 1.21 & 2.17 & 1.60 & 2.17 & 1.00 & 1.00 & 4.71 \\
\hline 8 & 10 & 40 & 0.18 & 0.73 & 0.22 & 0.73 & 1.00 & 1.00 & 0.53 \\
\hline 9 & 11 & 45 & 0.17 & 0.66 & 0.20 & 0.66 & 1.00 & 1.00 & 0.44 \\
\hline 10 & 13 & 50 & 0.18 & 0.67 & 0.22 & 0.67 & 1.00 & 1.00 & 0.45 \\
\hline 11 & 25 & 100 & 0.08 & 0.41 & 0.10 & 0.41 & 1.00 & 1.00 & 0.17 \\
\hline
\end{tabular}

S: Seviye, ÖS: Özellik Sayısı, ÖY: Özellik Yüzde

Diastolik kan basıncının hesaplanması için 11 model önerilmiştir ( 
Tablo 4). Model MAPE değerleri değerlendirildiğinde seviye 8 ile en başarılı model oluşturulmuştur. Özellik seçme algoritmasının performansı arttırdığı söylenebilir. Burada, tüm özellikler (25) (Seviye 11) ile MAPE değeri 0.14 olarak elde edilirken seviye 8'de sadece 10 adet özellik ile 0.13 değeri elde edilmiştir. 
Tablo 4. Diastolik kan basıncı hesaplanması için model performansları

\begin{tabular}{cccccccccc} 
& Bilgi & \multicolumn{8}{c}{ Performans Değerlendirme Kriterleri } \\
\hline S & ÖS & ÖY & MAPE & RMSE & MAD & SH & R & $\mathbf{R}^{\wedge} \mathbf{2}$ & MSE \\
\hline 1 & 1 & 5 & 6.11 & 5.96 & 4.50 & 5.97 & 1.00 & 1.00 & 35.58 \\
\hline 2 & 3 & 10 & 5.97 & 7.15 & 4.31 & 7.15 & 0.63 & 0.39 & 51.05 \\
\hline 3 & 4 & 15 & 0.52 & 2.24 & 0.36 & 2.24 & 1.00 & 1.00 & 5.03 \\
\hline 4 & 5 & 20 & 0.63 & 1.20 & 0.41 & 1.20 & 1.00 & 1.00 & 1.45 \\
\hline 5 & 6 & 25 & 0.49 & 0.86 & 0.32 & 0.86 & 1.00 & 1.00 & 0.75 \\
\hline 6 & 8 & 30 & 0.77 & 34.52 & 0.82 & 34.53 & 1.00 & 1.00 & 1191.54 \\
\hline 7 & 9 & 35 & 0.22 & 3.35 & 0.16 & 3.36 & 1.00 & 1.00 & 11.25 \\
\hline $\mathbf{8}$ & $\mathbf{1 0}$ & $\mathbf{4 0}$ & $\mathbf{0 . 1 3}$ & $\mathbf{0 . 4 7}$ & $\mathbf{0 . 0 7}$ & $\mathbf{0 . 4 7}$ & $\mathbf{1 . 0 0}$ & $\mathbf{1 . 0 0}$ & $\mathbf{0 . 2 2}$ \\
\hline 9 & 11 & 45 & 0.54 & 0.99 & 0.34 & 0.99 & 1.00 & 1.00 & 0.98 \\
\hline 10 & 13 & 50 & 2.12 & 4.26 & 1.54 & 4.27 & 1.00 & 0.99 & 18.18 \\
\hline 11 & 25 & 100 & 0.14 & 0.55 & 0.08 & 0.55 & 1.00 & 1.00 & 0.30 \\
\hline
\end{tabular}

\section{Tartışma}

Çalışmanın amacı ECG sinyali ile yapay zeka tabanlı holter monitörlerine uygulanabilir sistolik ve diastolik kan basıncı hesaplama süreci geliştirmektedir. Holter monitörleri hasta izlemede sıklıkla kullanılan ve pratik bir cihazdır. Bu monitörlerin yazılımsal olarak geliştirilmesi hastaların daha sağlıklı bir şekilde izlenmesinde aktif rol oynayacaktır. Bilindiği üzere günümüzde elektronik donanım ve parçaların ucuzlamasıyla cihazlara katma değer katan şey yazılımdır. Bu bakımdan çalışmanın en özgün yanı mikroişlemcilere uygulanabilir bir makine öğrenmesi algoritması seçilmiştir.

Osilometrik dalga formları kan basıncının hesaplanmasında kullanılabilir [7], [9]. Ancak bu sinyallerin işlenmesinde ve elde edilmesinde farklı mekanizmalar gerekebilir. Ayrıca sinyallerin işleyişi için de farklı teknikler gerekebilir. ECG sinyalinin elde edilişinin daha kolay olması bakımından bu çalışma literatüre kıyasla daha kolay uygulanabilir süreç içermektedir. ECG'nin sinyal işleme sürecinde bu çalışmada istatistiksel özellikler kullanıldığı için sinyal işleme süreci diğer çalışmalara kıyasla daha kolaydır [5], [6], [8], [10].

Literatürde derin öğrenme gibi yüksek performansa sahip makine öğrenmesi algoritmalar tercih edilmektedir [5]-[11]. Ancak bu yöntemlerin gömülü sistemlerde uygulanabilirliği oldukça zahmetlidir. Bu çalışmada gömülü sistemlerde sıklıkla kolay uygulanabilen yapay sinir ağları tercih edilmiştir. Bu bakımdan kan basıncı tahmin sürecinde oldukça kolay bir süreç içermektedir.

Sistolik ve diastolik kan basıncı tahmin modelleri R ve MSE performans değerleri sırasıyla 1, 0,0112 ve $1,0,0054$ olarak tespit edilmiştir. Çalışmanın performansı literatür ile kıyaslandığında oldukça yüksek bir başarım oranına sahiptir. Her ne kadar bazı derin öğrenme algoritmaları daha iyi performansa sahip olsa da, uygulama şansının olması durumunda belirli oranda başarım değerinden vazgeçilebilir. Ancak burada vazgeçilen değer önemli bir boyutta değildir. 


\section{Sonuç}

Bu çalışmada elde edilen sonuçlara göre ECG sinyali ile yapay zeka tabanlı geliştirilen kan basıncı hesaplama sürecinin Holter monitörlerinde kullanılabileceği değerlendirilmektedir. Literatür ile kıyasladığında çalışmada yer olan güncel yenilikler şu şekildedir. (1) ECG sinyalinin istatistiksel işleme süreci ile daha az sinyal işleme yükünün oluşmaktadır. (2) Özellik seçme algoritması model performanslarını arttırmıştır. (3) Yapay sinir ağları modeli mikroişlemcilere uygulanabilmektedir. (4) Önerilen modeller 0.01-0.005 gibi çok düşük MSE hata oranı ile yüksek doğruluk oranına sahiptir. Çalışmanın sonuçlarına göre önerilen modelin Holter monitörlerinde kullanılabileceği değerlendirilmektedir.

\section{Kaynaklar}

[1] P. D. Karakurt, "Hipertansiyon ve Evde Bakım," Atatürk Üniversitesi Hemşirelik Yüksekokulu Derg., vol. 10, no. 1, pp. 97-104, 2007, Accessed: Jun. 03, 2021. [Online]. Available: https://dergipark.org.tr/en/pub/ataunihem/issue/2636/33917.

[2] World Health Organization, "A global brief on hypertension | World Health Day 2013," Switzerland, 2013. Accessed: Jul. 05, 2021. [Online]. Available: www.who.int.

[3] World Health Organization, "Hypertension," World Health Organization, 2021. https://www.who.int/news-room/fact-sheets/detail/hypertension (accessed Jul. 05, 2021).

[4] E. Öncü, "Sağlık Okuryazarlığının Hipertansiyon Kontrolünde Önemi," Dünya İnsan Bilim. Derg., vol. 2018, no. 1, pp. 45-70, May 2018, Accessed: Jun. 03, 2021. [Online]. Available: https://dergipark.org.tr/en/pub/insan/694112.

[5] J. Esmaelpoor, M. H. Moradi, and A. Kadkhodamohammadi, "A multistage deep neural network model for blood pressure estimation using photoplethysmogram signals," Comput. Biol. Med., vol. 120, p. 103719, May 2020, doi: 10.1016/j.compbiomed.2020.103719.

[6] A. Soltan zadi, R. Alex, R. Zhang, D. E. Watenpaugh, and K. Behbehani, "Arterial blood pressure feature estimation using photoplethysmography," Comput. Biol. Med., vol. 102, pp. 104-111, Nov. 2018, doi: 10.1016/j.compbiomed.2018.09.013.

[7] A. S. Alghamdi, K. Polat, A. Alghoson, A. A. Alshdadi, and A. A. Abd El-Latif, "A novel blood pressure estimation method based on the classification of oscillometric waveforms using machine-learning methods," Appl. Acoust., vol. 164, p. 107279, Jul. 2020, doi: 10.1016/j.apacoust.2020.107279.

[8] Ü. Şentürk, K. Polat, and İ. Yücedağ, “A non-invasive continuous cuffless blood pressure estimation using dynamic Recurrent Neural Networks," Appl. Acoust., vol. 170, p. 107534, Dec. 2020, doi: 10.1016/j.apacoust.2020.107534.

[9] Ü. Şentürk, K. Polat, and İ. Yücedağ, "Towards wearable blood pressure measurement 
systems from biosignals: a review," Turkish J. Electr. Eng. Comput. Sci., vol. 27, no. 5, pp. 3259-3281, Oct. 2019, doi: 10.3906/elk-1812-121.

[10] C. Landry, E. T. Hedge, R. L. Hughson, S. Peterson, and A. Arami, "Accurate Blood Pressure Estimation during Activities of Daily Living: A Wearable Cuffless Solution," IEEE J. Biomed. Heal. Informatics, 2021, doi: 10.1109/JBHI.2021.3054597.

[11] C. Landry, E. T. Hedge, R. L. Hughson, S. D. Peterson, and A. Arami, "Wearable Physiological and Blood Pressure Measurements During Activities of Daily Living," IEEE Dataport, 2021, doi: https://dx.doi.org/10.21227/wysp-gt69.

[12] R. Alpar, Uygulamalı istatistik ve geçerlilik güvenirlilik: Spor, sağlık ve eğitim bilimlerinden örneklerle, 2nd ed. Ankara: Detay Yayıncılık, 2016.

[13] K. Polat and K. Onur Koc, "Detection of Skin Diseases from Dermoscopy Image Using the combination of Convolutional Neural Network and One-versus-All," J. Artif. Intell. Syst., vol. 2, no. 1, pp. 80-97, Feb. 2020, doi: 10.33969/ais.2020.21006.

[14] M. K. Ucar, S. Orenc, M. R. Bozkurt, and C. Bilgin, "Evaluation of the relationship between Chronic Obstructive Pulmonary Disease and photoplethysmography signal," in 2017 Medical Technologies National Congress (TIPTEKNO), Oct. 2017, pp. 1-4, doi: 10.1109/TIPTEKNO.2017.8238032.

[15] M. K. Uçar, Z. Uçar, K. Uçar, M. Akman, and M. R. Bozkurt, "Determination of body fat percentage by electrocardiography signal with gender based artificial intelligence," Biomed. Signal Process. Control, vol. 68, p. 102650, Jul. 2021, doi: 10.1016/j.bspc.2021.102650.

[16] M. K. Uçar, M. Nour, H. Sindi, and K. Polat, "The Effect of Training and Testing Process on Machine Learning in Biomedical Datasets," Math. Probl. Eng., vol. 2020, pp. 1-17, 2020, doi: 10.1155/2020/2836236. 